Tире vs. двоеточие - чувство против разума?

Аннотация: В статье рассматриваются особенности современной пунктуации в публичном дискурсе, агрессивная экспансия тире и замена им двоеточия. Оппозиция «правильная / неправильная» пунктуация, определяющая языковую ситуацию во второй половине XX века, уступила место противопоставлению «школьная / peальная» в начале XXI. Автор отмечает, что замена двоеточия на тире в большинстве бессоюзных предложений может быть вызвана ослаблением причинных связей частей высказывания в сознании говорящих. Высказывается предположение о смене стратегии убеждения: от логики аргументации к передаваемой эмоции.

Ключевые слова: вариативная пунктуация, тире, двоеточие, оппозиция, эмоциональная пауза, рефлексирующая пауза

Yu.V. Egorova (Moscow, Russia)

\title{
Dash vs. Colon - Sensibility vs. Sense?
}

Abstract: The article discusses the features of modern punctuation in public discourse, the aggressive expansion of the dash and the replacement of the colon with it. The opposition "correct / incorrect" punctuation which determined the language situation in the second half of the the $20^{\text {th }}$ century gave way to the opposition "school / real" at the beginning of the $21^{\text {st }}$ century. The author notes that the substitution of a colon for a dash in most conjunctionless sentences may be caused by the weakening of causal relationships in the minds of speakers. It is suggested that the pattern of strategy of persuasion and influence on the addressee has changed: from the logic of the argument to transmitted emotion.

Key words: variable punctuation, dash, colon, opposition, emotional pause, reflective pause

Традиционно знаки препинания - герои школьных учебников и пособий по пунктуации. Лишь иногда они становятся объектом исследования ученых. Так, внимание Б.С. Шварцкопфа привлекли новации в постановке кавычек в газетно-журнальной практике в 1960-х гг; в статье он объясняет их активное использование «необходимостью каким-то образом выражать на письме различные и 
весьма сложные смысловые оттенки, чаще всего переносный характер слов и выражений [Шварцкопф 1967: 61], наделяет рассматриваемый знак препинания «оценочно-стилистической» функцией. Анна А. Зализняк, продолжая исследовать семантику кавычек, выделяет их инвариантное значение - «разрушение стандартного семиотического знака в письменной речи» [Зализняк 2007].

К пунктуации обращались исследователи, отмечающие особенности использования того или иного знака препинания и его смысловую нагруженность в творчестве отдельного автора как маркера его индивидуального стиля и идеоязыка (тире у М. Цветаевой, В. Маяковского, В. Пелевина, скобки у А. Солженицына и т. д.). Современный филологический дискурс, посвященный знакам препинания, отмечает разрушение нормативной пунктуации, закрепленной правилами 1956 года, увеличение вариативной и авторской пунктуации [Валгина 2003]. Одним из активных процессов такого рода стала агрессивная экспансия тире.

Не надо быть профессиональным лингвистом, чтобы осознать: в письменной коммуникации двоеточие как знак пунктуации уступает место тире. Интересно, что на этот «настоящий кризис» двоеточия обратили внимание прежде всего журналисты. «Под натиском нахрапистого тире, которое буквально расталкивает части предложения локтями, скромное двоеточие теряется, прячется, отходит на второй на десятый план», - пишет К. Туркова в статье «Общение в сети: что случилось с пунктуацией?» (www.pravmir.ru/obshhenie-v-seti-chto-sluchilos-s-punktuatsiey/).

Тире - молодой пунктуационный знак. В «Российской грамматике» М.В. Ломоносова оно не упоминается, появляясь вместе с кавычками и многоточием только во второй половине XVIII в. Даже в начале XIX в. тире воспринимается как нововведение, против него возражают архаисты: «Черточки (тире) есть также новое изобрђтеніе, показующее больше упадокъ, нежели возвышеніе ум» (А.С. Шишков. Письма И. Дмитриеву, 1818-1821)ํ.

B печатных текстах XIX в. функции тире и двоеточия, по-видимому, не были четко разграничены. Так, Н.С. Валгина отмечает даже значительно более частое употребление двоеточия: «Я был готов любить весь мир, - меня никто не понял: и я выучился ненавидеть» (М.Ю. Лермонтов. «Герой нашего времени») [Валгина 2001: 243]. В данном случае двоеточие оформляет сочинительную связь и указывает на последовательность событий, что является явным нарушением с точки зрения современной нормативной пунктуации, когда подобное семантическое содержание приписывается тире.

В пособиях по пунктуации для школьников и редакторов, наряду с нормативной, иногда оговаривается и относительно регулярная авторская пунктуация. Так, упоминаются случаи постановки тире между подлежащим и сказуемым, когда норма это запрещает («Бедность - не порок»), но мы не встретим там ни ритмико-эмфатическое тире М. Цветаевой: «Как на знак тире - / Что на тайный знак / Брови вздрагивают - / заподазриваешь?» («В седину - висок», 1925), ни обозначающее недосказанность тире Ф. Тютчева в конце строк стихотворения «1 декабря 1837».

Русская нормативная пунктуация, как известно, опирается на структурный принцип, а отнюдь не на эмоционально-интонационный. В течение второй половины XX в., в период, по-видимому, наибольшей пунктуационной стабильности, в учебном, публичном и, прежде всего, медийном дискурсе актуальной была оппозиция «нормированная / ненормированная пунктуация», в большинстве слу-

\footnotetext{
${ }^{1}$ Примеры без указаний на конкретный печатный источник взяты из Национального корпуса русского языка (www.ruscorpora.ru/index.html).
} 
чаев синонимичная противопоставлению «правильная / неправильная». Данная оппозиция значительно облегчала работу учителей и корректоров: понятно, как проверять, оценивать и исправлять. Вариативность также была оговорена, зафиксирована сводом правил. Последние двадцать лет значительно усложнили ситуацию. Массовое авторство, широкое использование разговорных конструкций в публичной письменной речи, ориентация на свободу самовыражения, ослабление института корректуры - все это повлияло на содержание оппозиции. Она видоизменяется и тяготеет к виду «школьная / реальная». Об этом свидетельствуют, например, сайты, содержащие описание вариативных случаев употребления знаков препинания, в частности, тире вместо двоеточия. Авторы этих рекомендаций в большинстве своем, конечно, не члены орфографических комиссий, не корректоры. Тексты подобной тематики встречаются чаще всего на сайтах и личных страницах активно пишущих людей: поэтов, блогеров. Авторы фиксируют значительное расширение функций тире, вариативность постановки знаков в случаях, ранее признанных однозначными.

На портале «Стихи.ру» этой теме посвящен отдельный текст: «Не все знаки препинания применимы однозначно: некоторые из них могут заменять друг друга, использоваться параллельно или ВАРИАТИВНО (быть представленными несколькими допустимыми вариантами)» (www.stihi.ru/2015/10/29/9795). Сгустком вариативности автор поста считает параллельное употребление двоеточия и тире. Такими ситуациями, согласно мнению пишущего, считаются следующие: 1) после обобщающего слова перед перечислением однородных членов предложения; 2) в бессоюзном предложении с «изъяснительными» отношениями; 3) «в эллиптических предложениях с отсутствующим глаголом восприятия»; 4) в бессоюзных предложениях с причинно-следственными и пояснительными отношениями. В то же время классические пособия по пунктуации последние три случая вариативными не считают. Их лексическое описание в тексте поста противоречиво: с одной стороны, автор употребляет слово «вариативный», что свидетельствует о регулярной возможности замены; с другой - использует глагол «встречается», что, скорее, говорит о наблюдаемых случаях, о тенденции, но никак не о системном правиле. Активная экспансия тире в последнее время не новость, особенно в средствах массовой информации, да и свод правил 1956 г. устарел и, несомненно, нуждается в корректировке, но без формального закрепления пунктуационных изменений «агрессия» тире не дает нам права считать эти случаи вариативными.

С их вариативностью, пожалуй, не согласился бы ни один учитель русского языка, в работах школьников эти «вариативные» тире исправляются как ошибки. С обилием подобных ошибок столкнулись в этом году преподаватели МГУ, проверяющие выпускные сочинения по литературе. Согласно моему опыту, это была самая распространенная ошибка после пропуска запятой в конце придаточного предложения или причастного оборота:

Татьяна не может изменить свою судьбу - ее разум напоминает ей о долге замужней женщины.

В этом примере из школьного сочинения вторая часть бессоюзного предложения, несомненно, говорит о причине сообщаемого в первой, нет отношений ни противопоставления, ни следствия, ни быстрой смены событий, что каким-либо образом оправдало бы постановку тире. Это не единичный случай, редко обратное: большинство выпускников предпочитают не использовать двоеточия, вместо 
него ставят тире. Конечно, можно объяснить это снижением пунктуационной грамотности, на что уже десятилетия сетует публичный дискурс:

Отсутствующие запятые и не в том месте проставленное тире, причем в цитате, - это уже общие места ${ }^{1}$.

Однако, по моему мнению, лишь отчасти экспансия тире объясняется пунктуационной некомпетентностью. Предпочтение тире двоеточию симптоматично, это знак времени, когда эмоционально-интонационное воздействие на слушающего / читающего оказывается эффективнее логически-рационального.

Подобной заменой грешат не только неуверенные в себе школьники, но и современные редакторы, о чем свидетельствует, например, высказывание интернет-пользователя. На уже упоминаемом портале «Стихи.ру», в ветке «Деградация устной и письменной речи», в ходе обсуждения авторских знаков препинания встретилось следующее замечание одного из участников: «Мне (вопреки смысловой логике) московский редактор заменил почти все двоеточия на тире (а Вы о Цветаевой). Я не стал оспаривать: чем бы дитя ни тешилось. Так книга и вышла с тире. Единственное тому оправдание - двоеточие не так заметно при беглом прочтении текста, как тире» (www.stihi.ru/2016/03/20/5091).

Соперничество тире и двоеточия в ситуациях, когда современные пособия по пунктуации настоятельно рекомендуют двоеточие, можно сравнить с хрестоматийным противостоянием разума и чувства. «Двоеточие - умный, размышляющий знак: обычно оно предшествует объяснению, аргументу» (www.pravmir.ru/obshhenie-vseti-chto-sluchilos-s-punktuatsiey/). Двоеточие на письме, как и тире, свидетельствует об интонационной паузе, но она несколько иного свойства, чем пауза тире. Условно ее можно было бы назвать рефлексирующей паузой: говорящий / пишущий остановился, «притормозил», чтобы объяснить причины сообщаемого, подобрать более подходящие слова, уточнить, что он имел в виду. Двоеточие как будто заставляет нас быть более логичными, приводить аргументы, искать мотивы поступков и действий.

Тире в бессоюзном предложении - знак эмоциональной паузы. Со сферой чувств этот знак препинания связывался еще в начале XX в. В «Записных книжках» Л. Гинзбург вспоминает: «Л.В. Щерба рассказал, что Бодуэн де Куртенэ вычеркивал в работах своих учеников тире, которое он называл “дамским знаком”... Он усматривает в употреблении тире и курсивов признак нелогичности или лености пишущего, который пользуется не прямыми, а добавочными средствами выражения мысли... Корн.Ив. Чуковский дал мне как-то менее уничижительное толкование этому пристрастию: “Тире - знак нервный, знак девятнадцатого века. Невозможно вообразить прозу восемнадцатого века, изобилующую тире»² [Гинзбург 2002]. Ассоциация «тире - эмоция»- один из закрепленных паттернов в понимании семантического содержания этого знака препинания. Это находит отражение в большинстве контекстов национального корпуса русского языка, когда речь не идет об ошибках пишущего:

Многочисленные эмоциональные тире и многоточия еще более подчеркивают возбужденное состояние героя [Феликс Раскольников. Статьи о русской литературе (1986-2000)].

\footnotetext{
${ }^{1}$ См.: Колесников Андрей. Война шершавых языков (2003) // Известия. 2003. 24 июля.

${ }^{2}$ Конечно, аргумент К.И. Чуковского не совсем убедителен. Несмотря на то что вслед за писателем нам бы хотелось считать XVIII в. в России временем рационального и позитивистского, почти декартовского мышления, чуждого эмоциональных всплесков, мы не должны забывать, что тире как знак препинания в этот период просто не употреблялось.
} 
Обилие эмоциональных тире уверенно связывают с русской письменной традицией, с женским авторством посланий, «зашкаливающими» эмоциями:

Вслед за Бодуэном Щерба полагает, что тире, равно как и подчеркивания (в печати курсив), попало в литературу из эмоциональных форм: письма, дневника: Сейчас письма не пишут. А прежде писали много, особенно женщины, - и многие очень хорошо писали [Гинзбург 2002].

Письма были длинные, страстные, сумбурные, со множеством сокращений, тире, многоточий, помарок, неправильных переносов и восклицательных знаков. (В.П. Катаев. «Время, вперед!», 1931-1932).

Вторичная же устная речь реагирует на воспроизводимый письменный первоисточник, стремится интонационно следовать ему. Авторы, описывающие чтение вслух, подчеркивают, что говорящий старается выделить тире:

Он читал с восторгом «Бедную Лизу» и любил везде ставить тире, в подражание модному тогда Карамзину (Н.И. Греч. «Записки о моей жизни», 1849-1856).

Интересно отметить, что паузам, оформляемым тире или двоеточием, разным по содержанию, может приписываться и разная длительность. А.И. Куприн использует эпитет небольшой для характеристики молчания, вызванного двоеточием на письме:

Он делает небольшим молчанием двоеточие, совсем маленькое, всего в полторы секунды, но в этот короткий промежуток сотни тревожных мыслей пробегают в голове Александрова (А.И. Куприн. «Юнкера», 1932).

С тире в сознании носителей русского языка ассоциируется более длинная и выразительная пауза. Тире у В. Маканина «длящееся», а у К. Крылова сама пауза звучит, как тире:

Обращает внимание - задерживает дыхание: На жестяном листочке сохранилось нестертым только длящееся тире, выглядело так: (Владимир Маканин. «Утрата», 1984)

Время (он глотает граппу, отчего простая фраза обогащается паузой, звучащей как тире) - такое (Константин Крылов. «Время - такое», 2012).

В «Записках и выписках» М.Л. Гаспаров упоминает тире и кавычки как «знаки безответственности»:

Если я в газетной заметке возьму каждое слово в кавычки - она обретет фантастическую глубину: почти Андрей Белый. Кавычки - знак безответственности (как и тире). (М.Л. Гаспаров. «Записи и выписки», 2001).

С кавычками все в целом понятно: пишущий стремится «спрятаться» за чужое авторитетное высказывание, опереться на него. А вот «безответственность» двоеточия порождает вопросы. Осмелимся предположить, что это свойство тире связано с большой имплицитной частью в семантическом содержании этого знака препинания. Прописанные в пособиях по пунктуации смыслы, закрепленные за тире, соединяющим части бессоюзного предложения, не всегда легко опознаются. С противопоставлением более или менее ясно, чего не скажешь об условии / следовании. В программном «Лес рубят - щепки летят» постановка тире очевидна, но смысл отношений между частями можно определить и как условие в первом предложении, и как следствие - во втором.

В бессоюзных предложениях, когда вторая часть описывает то, на что указывает первая (Иду и вижу: кошка крадется по раскаленной крыше), двоеточие предупреждает нас о раскрытии видео- или аудиообраза, возникающего в сознании го- 
ворящего, скорее всего не привнося в отношения между частями никаких дополнительных смыслов. Автор текста, заменяющий в данном предложении двоеточие на тире (Иду и вижу - кошка крадется по раскаленной крыше), по-видимому, не только увеличивает паузу, но и подчеркивает эмоциональное состояние субъекта, причем не очень четко определяемое: то ли удивление, то ли восхищение, то ли страх за животное. Это затруднение в точном определении испытываемой субъектом эмоции, фиксируемой на письме тире, отражено в строчках В. Хотомской, посвященных знакам препинания:

В напрасных усильях, чтоб лоб не тереть,

Поэт вместо мыслей ставит тире...

(www.znaki-pr.ru/texts/znaki-pr_stihi\%26pics.html)

Таким образом, семантическое содержание тире на протяжении всего использования данного знака препинания неразрывно связано с эмоцией, при этом не всегда легко опознаваемой, становящейся частью имплицитного смысла предложения. И вот такой знак препинания стал необыкновенно востребован в современном письменном дискурсе, заменяя собой отражающее причинные связи двоеточие и появляясь в самых неожиданных местах.

При такой распространенности тире, однако, никогда не было знаком препинания, который был бы рекомендован к употреблению. Совсем наоборот: даже маститые литераторы предупреждали молодых авторов о необходимости ограничивать использование тире. Так, в воспоминаниях об А.П. Чехове А.И. Куприн приводит его советы писателям: «Также поменьше употребляйте кавычек, курсивов и тире это манерно» (А.И. Куприн. «Памяти Чехова. Он между нами жил...», 1905).

Современные пособия по деловой коммуникации, наверное, наиболее регламентированной сфере общения, призывают нас следовать утвержденным правилам пунктуации и избегать авторских вариантов. Другая картина в многочисленных «ветках», посвященных этой теме. Большинство активных участников, поднимающих эту тему, - апологеты тире. Вот пример такой точки зрения, встретившийся в формате самостоятельного высказывания на портале thequestion.ru/ru/ feed: «Поскольку этот знак препинания в русском языке является “знаком широкого назначения" (касающихся его правил и рекомендаций - более двух десятков), то в случае сомнений в правильности постановки, например, запятой при явной интонационной паузе - лучше все же поставить тире, чем пробел. Конечно, если написанное не предназначено для проверки и последующей оценки грамотности.

Почти любое предложение, особенно сложное, включающее обороты, трудно испортить постановкой тире, а вот пропустив указание на отдельные части, очень легко ввести читающего в заблуждение.» (thequestion.ru/questions/3322/mozhno-livezde-gde-ne-znaesh-kakoi-znak-prepinaniya-stavit-tire).

Обилие эмоционального и интонационного тире в публичном дискурсе, по-видимому, демонстрирует смену стратегии убеждения. При замене двоеточия на тире говорящий опирается не на логику слушающего, для чего важны аргументы и причинно-следственные связи, а на его эмоциональное состояние, на которое можно повлиять. Именно подобное воздействие оказывается эффективным сегодня, что закрепляет постановку тире там, где оно раньше не встречалось в нормированном дискурсе. Однако аргументация и спокойный анализ положения дел - вещь отнюдь не лишняя в современном социуме, поэтому хочется защитить такой знак препинания, как двоеточие. Его связь с порядком и рассудительностью 
подчеркивается даже в детских стихах С.Я. Маршака о знаках препинания, когда слово предоставляется самому двоеточию:

В оба глаза я гляжу.

За порядком я слежу

(www.znaki-pr.ru/texts/znaki-pr_stihi\%26pics.html).

\section{ЛИТ ЕРТ У РА}

Валгина Н.С. Активные процессы в современном русском языке: Учебное пособие. М.: Логос, 2003. 304 c.

Гинзбург Л. Записные книжки. Воспоминания. Эссе. СПб.: Искусство, 2002, 254 с.

Зализняк Анна А. Семантика кавычек // Труды Международного семинара Диалог'2007 по компьютерной лингвистике и ее приложениям. М., 2007 (philology.ru/linguistics2/zaliznyak_anna-07.htm)

Знаки препинания. Py. www.znaki-pr.ru/texts/znaki-pr_stihi\%26pics.html

Национальный корпус русского языка. www.ruscorpora.ru/index.html

Стихи.py. http://www.stihi.ru/2016/03/20/5091

Туркова $K$. Общение в сети: что случилось с пунктуацией? www.pravmir.ru/obshhenie-v-seti-chto-sluchilos-s-punktuatsiey

Шварикопф Б.С. Внимание: кавычки! // Русская речь. 1967. № 4. С. 60-64.

\section{REFERENCES}

Valgina N.S. (2003) Active Processes in the Modern Russian Language: Textbook. M. Logos Publ. 304p.

Ginzburg L. (2002) Diaries. Memories. Essays. St.-Petersbutg. Iskusstvo Publ. 254 p.

Zaliznjak Anna A. The Semantics of the Quotation Marks. In: The International Workshop on Computational Linguistics and Its Applications Dialog'2007. Moscow. 2007. philology.ru/ linguistics2/zaliznyak_anna-07.htm

Znaki Prepinanija.ru. /www.znaki-pr.ru/texts/znaki-pr_stihi\%26pics.html

Russian National Corpus. www.ruscorpora.ru/index.html

Stihi.ru. www.stihi.ru/2016/03/20/5091

Turkova K. Communication in the Network: What Happened to Punctuation? www.pravmir. ru/obshhenie-v-seti-chto-sluchilos-s-punktuatsiey

Shvarchkopf B.S. Attention: The Quotation Marks! Russkaya Rech. 1967. No 4, pp. 60-64.

Сведения об авторе:

Юлия Викторовна Егорова, кандидат культурологии

доцент

кафедра лингвистики, перевода и межкультурной коммуникации

факультета иностранных языков и регионоведения

МГУ имени М.В. Ломоносова
Yulia V. Egorova,

$\mathrm{PhD}$

Associate Professor

Department of Linguistics, Translation Studies and Intercultural Communication

Faculty of Foreign Languages and Area Studies

Lomonosov Moscow State University

iegorova64@yandex.ru 